\title{
Assessment of tegumental damage to Schistosoma mansoni and S. haematobium after in vitro exposure to ferrocenyl, ruthenocenyl and benzyl derivatives of oxamniquine using scanning electron microscopy
}

Valentin Buchter ${ }^{1,2}$, Jeannine Hess ${ }^{3}$ (D), Gilles Gasser ${ }^{4}$ (D) and Jennifer Keiser ${ }^{1,2^{*}}$ (D)

\begin{abstract}
Background: Schistosomiasis is one of the most harmful parasitic diseases worldwide, praziquantel being the only drug in widespread use to treat it. We recently demonstrated that ferrocenyl, ruthenocenyl and benzyl derivatives of oxamniquine (Fc-OXA, Rc-OXA and Bn-OXA) are promising antischistosomal drug candidates.

Methods: In this study we assessed the tegumental damage of these three derivatives of oxamniquine using scanning electron microscopy. Adult Schistosoma mansoni and S. haematobium were exposed to a concentration of $100 \mu \mathrm{M}$ of each drug and incubated for 4-120 h, according to their onset of action and activity.

Results: While on S. mansoni the fastest acting compound was Fc-OXA, which revealed high activity after $4 \mathrm{~h}$ of incubation, on S. haematobium, Rc-OXA revealed the quickest onset, being lethal on all males within $24 \mathrm{~h}$. In both species studied, the three derivatives showed the same patterns of tegumental damage consisting of blebs, sloughing and tegument rupturing all over the body. Additionally, on S. mansoni distinct patterns of tegumental damage were observed for each of the compounds: tissue ruptures in the gynaecophoric canal for Fc-OXA, loss of spines for Rc-OXA and oral sucker rupture for Bn-OXA.

Conclusions: Our study confirmed that Fc-OXA, Rc-OXA and Bn-OXA are promising broad spectrum antischistosomal drug candidates. All derivatives show fast in vitro activity against S. mansoni and S. haematobium while validating the previous finding that the parent drug oxamniquine is less active in vitro under the conditions described. This work sets the base for further studies on the identification of a lead oxamniquine derivative, with the aim of identifying a molecule with the potential to become a new drug for human use.
\end{abstract}

Keywords: Schistosomiasis, Organometallic derivatives, Oxamniquine, Schistosoma mansoni, Schistosoma haematobium, Scanning electron microscopy

\footnotetext{
* Correspondence: jennifer.keiser@swisstph.ch

${ }^{1}$ Department of Medical Parasitology and Infection Biology, Swiss Tropical

and Public Health institute, Socinstrasse 57, 4051 Basel, CH, Switzerland

${ }^{2}$ University of Basel, P.O. Box, 4003 Basel, CH, Switzerland

Full list of author information is available at the end of the article
}

(c) The Author(s). 2018 Open Access This article is distributed under the terms of the Creative Commons Attribution 4.0 International License (http://creativecommons.org/licenses/by/4.0/), which permits unrestricted use, distribution, and reproduction in any medium, provided you give appropriate credit to the original author(s) and the source, provide a link to the Creative Commons license, and indicate if changes were made. The Creative Commons Public Domain Dedication waiver (http://creativecommons.org/publicdomain/zero/1.0/) applies to the data made available in this article, unless otherwise stated. 


\section{Background}

Schistosomiasis is a human parasitic disease that affected 230 million people worldwide in 2014 [1] and is caused by the infection with one or more of the six Schistosoma species: Schistosoma mansoni, S. haematobium, S. japonicum, S. mekongi, S. intercalatum and S. guineensis; the first three are the most important human species [1]. Because no vaccine is available, and the use of molluscicides to control the intermediate host is difficult to conduct, the most commonly used strategy to control the disease is preventative chemotherapy through large-scale administration of praziquantel [2]. Praziquantel, developed in the 1970's, is safe and effective, but has some shortcomings: the tablets are big because of the large dose needed, it is very bitter [3] and the drug is not active against juvenile forms of the parasite [4]. Frequent retreatment of patients is therefore required to target all parasite stages. Oxamniquine (OXA) is a drug that was developed in the 1960's [5] and proved to be effective and safe, but has two shortcomings: it is only active against $S$. mansoni [5-7] and resistance developed quickly due to punctual mutations to the enzyme's active site [8]. OXA is a pro-drug that for activation needs to be taken up by the worm and sulfonated by a sulfotransferase (SmSULT) to an unstable intermediate that spontaneously decays to a highly electrophilic molecule that alkylates DNA, proteins and macromolecules, thus interfering with its metabolic functions and killing the parasite [9]. Enzyme orthologs are present also in S. japonicum and $S$. haematobium and in mammalian cells, but differences in the interaction in the active site prevent the activation of the molecule $(70 \%$ protein sequence homology between $S$. haematobium and $S$. mansoni) [9]; therefore the drug is not active against S. haematobium [6]. The SmSULT expression in juvenile stages of the parasite has not yet been studied; however, OXA is known to be only slightly active against larval stages of S. mansoni [10]. Aiming to overcome this species and stage specificity through improved interaction with the target enzyme, we previously tested six OXA derivatives primarily based on organometallic derivatization due to its medicinal potential [11, 12] and identified three molecules (ferrocenyl, ruthenocenyl and benzyl derivatives of oxamniquine, named Fc-OXA, Rc-OXA and Bn-OXA, respectively) (Fig. 1) with a promising in vivo and in vitro activity profile against $S$. mansoni. Importantly, these compounds also displayed activity in vitro against S. haematobium [11].

The aim of the present study was to assess the damage to the tegument of S. mansoni and S. haematobium, evidenced by scanning electron microscopy (SEM) following incubation with Fc-OXA, Rc-OXA and Bn-OXA at the time points where the in vitro viability of the worms was markedly affected. Considering the importance of the tegument for schistosomes, which allows them to evade the immune response of the host, SEM is a valuable approach to identify whether the molecules can induce damage to this critical structure [13], and hence expose immune-reactive molecules and trigger an immune response in the host.

\section{Methods}

\section{Adult S. mansoni worms}

Three week-old female NMRI mice $(n=7)$ were purchased from Charles River and were allowed to acclimatize for one week. They were infected by a subcutaneous injection in the back of the neck with approximately 100 cercariae and kept in the animal facility of the Swiss TPH for 49 days to allow the infection to develop into the adult stage. Mice were then euthanized by the $\mathrm{CO}_{2}$ method and worms were collected by picking them from the hepatic portal system and mesenteric veins. Worms were washed in culture medium at room temperature and incubated at $37{ }^{\circ} \mathrm{C}$ with $5 \%$ $\mathrm{CO}_{2}$ until use (no longer than 2 days). The medium consisted of RPMI 1640 culture medium (Gibco Thermofisher, Waltham, MA USA) supplemented with $1 \%$ penicillin/streptomycin (BioConcept, Allschwil, Switzerland) and 5\% Fetal Calf Serum (FCS) (BioConcept). Eight to ten worms of both sexes per time

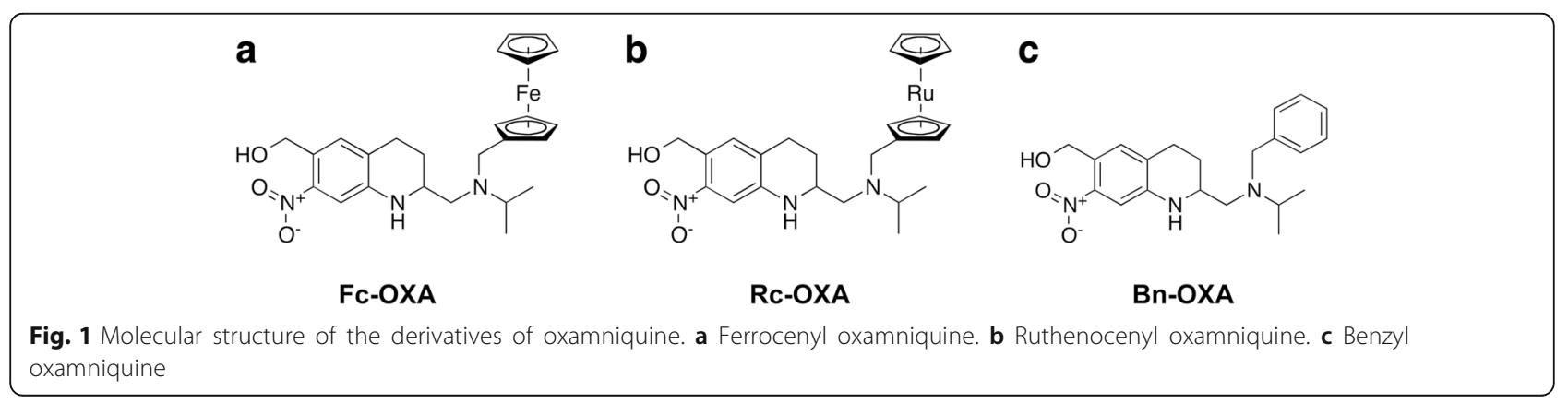


point were incubated in the described medium, in the presence of $100 \mu \mathrm{M}$ [11] of each of the three derivatives (Fc-OXA, Rc-OXA, Bn-OXA) and oxamniquine. The control consisted of 8-10 worms incubated in culture medium spiked with dimethyl sulfoxide (DMSO) at a concentration of $1 \%$, equivalent to the content of DMSO present in the wells of treated worms. Worms were monitored daily, scoring motility, viability and morphological alterations under a bright field inverted microscope (Carl Zeiss Oberkochen, Germany, magnification $\times 4$ and $\times 10$ ) as described elsewhere [14]. The scoring scale ranges from 3 to 0 with a 0.25 interval. The score 3 corresponds to fully vital worms showing normal movement and activity, and no morphological changes; 2 is assigned to slowed worm activity, first morphological changes (loss of attachment to the well plate, suckers deformity) and visible granularity; 1 is given if minimal activity, severe morphological changes (change of the color, loss of transparency, rounded body disposition) and marked granularity is observed; and 0 refers to dead worms revealing severe granularity.

Worms were collected for SEM analysis at the time point when the average viability of the worms was visibly affected. For each compound the onset of action was different, therefore the time points range from $4 \mathrm{~h}$ for Fc-OXA, to $24 \mathrm{~h}$ for Rc-OXA, to $72 \mathrm{~h}$ for Bn-OXA and $120 \mathrm{~h}$ for OXA.

\section{Adult S. haematobium worms}

One month-old male LVG hamsters (Charles River, NY) $(n=4)$ were exposed to $350 \mathrm{~S}$. haematobium cercariae at the Biomedical Research Institute in Rockville, USA (NR-21964), and shipped to the Swiss TPH where the infection was allowed to develop for three months until chronic infections had been established. The animals were kept in the animal facility until use, for a maximum of four months. Hamsters were euthanized by the $\mathrm{CO}_{2}$ method and worms picked from hepatic portal system and mesenteric veins. Briefly, 8-10 adult S. haematobium were exposed to a $100 \mu \mathrm{M}$ concentration for $24 \mathrm{~h}$ for ruthenocenyl oxamniquine, $48 \mathrm{~h}$ for ferrocenyl and benzyl oxamniquine and $120 \mathrm{~h}$ for oxamniquine, depending on the time needed for the worms to show a marked decrease in viability. Media used and scoring procedure were conducted as described for S. mansoni worms.
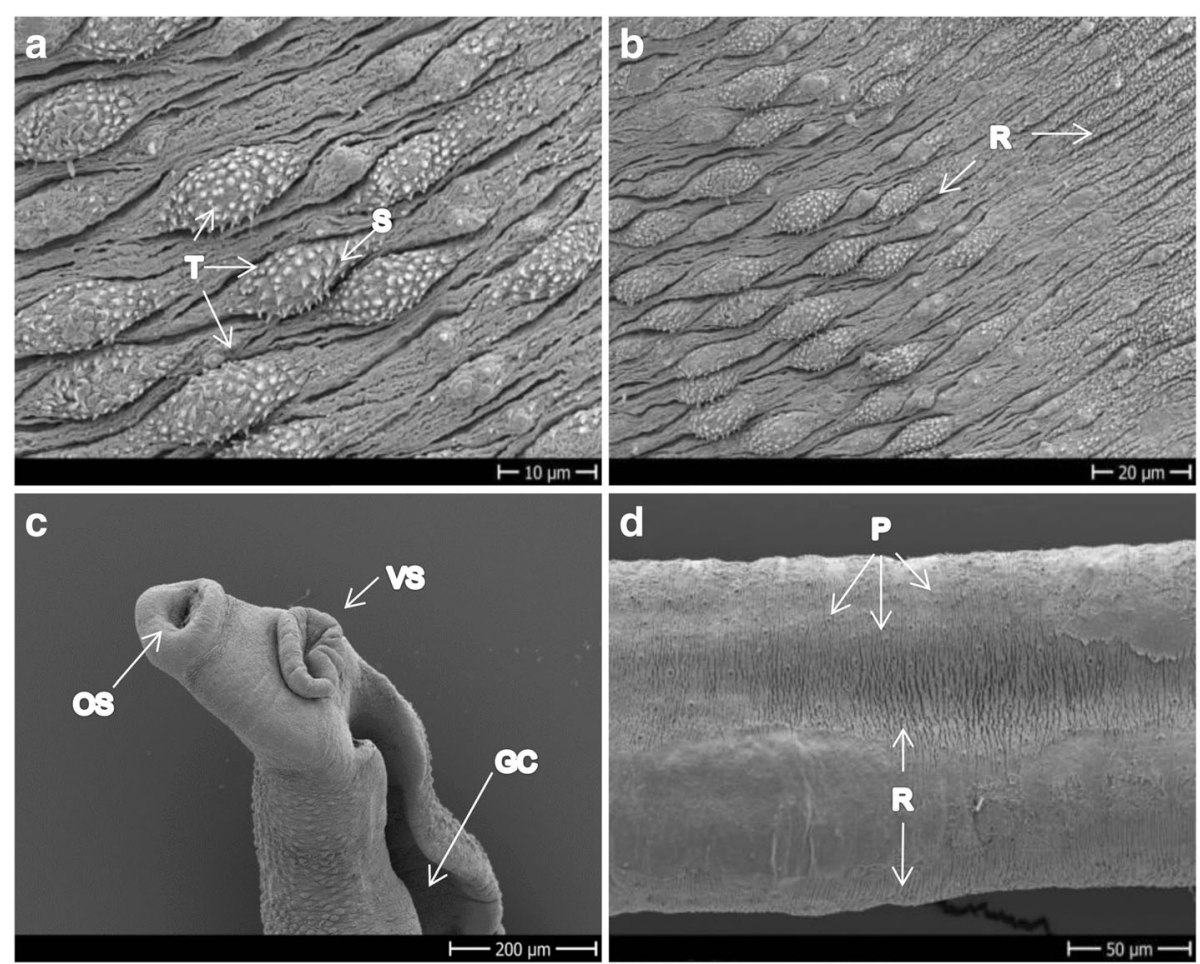

Fig. 2 SEM images of S. mansoni control worms incubated with 1\% DMSO. a Tubercles of dorsal mid-part of a male. b Lateral mid-part of a male showing the transition between the tubercles of the dorsal side to the spiny ridges of the ventral side of the body. $\mathbf{c}$ Head of a male showing the oral and ventral suckers and the gynaecophoric canal. $\mathbf{d}$ Mid-part of the body of a female showing the ridges and pores in a context of a smooth tegument. Abbreviations: GC, gynaecophoric canal; OS/NS, oral/ventral sucker; P, pores; R, ridges; S, spines; T, tubercles. Scale-bars: a, 10 $\mu \mathrm{m} ; \mathbf{b}, 20 \mu \mathrm{m} ; \mathbf{c}, 200 \mu \mathrm{m} ; \mathbf{d}, 50 \mu \mathrm{m}$ 


\section{Oxamniquine derivatives}

Oxamniquine was kindly donated by Pfizer (New York City, USA) while the Fc-OXA, Rc-OXA and Bn-OXA were prepared starting from oxamniquine, as described previously [11].

\section{SEM images}

Following the in vitro cultivation of the worms with the compounds as described above, S. mansoni and $S$. haematobium worms were rinsed twice in PBS, and fixed in $1 \mathrm{ml}$ glutaraldehyde $2.5 \%$ for $4 \mathrm{~h}$ at room temperature. Worms were then sequentially dehydrated by incubation for $30 \mathrm{~min}$ in increasing concentrations of ethanol in deionized water $(30,50$, 70,90 and 100\%) and kept in the fridge in 100\% ethanol until use. For imaging, worms were critically point-dried (Bomar SPC-900, Washington, USA), mounted on aluminum stubs and sputter-coated with gold of $20 \mathrm{~nm}$ particle size (Leica EM ACE 600, Heerbrugg, Switzerland). Samples were visualized using a high-resolution SEM accelerating voltage of 5 kV (Philips XL30 ESEM, Bruchsal, Germany). Control worms were prepared and visualized in the same manner. All images were taken in the Nano Imaging Lab, SNI, University of Basel.

\section{$\mathrm{IC}_{50}$ value calculations}

The $\mathrm{IC}_{50}$ values of each of the derivatives against $S$. haematobium were calculated using the software CompuSyn 1.0 (ComboSyn Inc, 2007) after $72 \mathrm{~h}$ of incubation with the following concentrations of each drug: 100, 50, 25, 12.5 and $6.25 \mu \mathrm{M}$. The equation to normalize the score of the treated worms to the controls and calculate the effect was:

$$
\text { Effect }=1-\left(\text { Average score }_{\text {treatment }} / \text { Average score }_{\text {control }}\right)
$$

The $\mathrm{IC}_{50}$ values obtained for the drugs on $S$. mansoni are described elsewhere [11].

\section{Results and discussion \\ Studies on S. mansoni}

Figure $2 \mathrm{a}$ and $\mathrm{b}$ shows the tegument of healthy adult $S$. mansoni males depicting ridges and tubercles covered
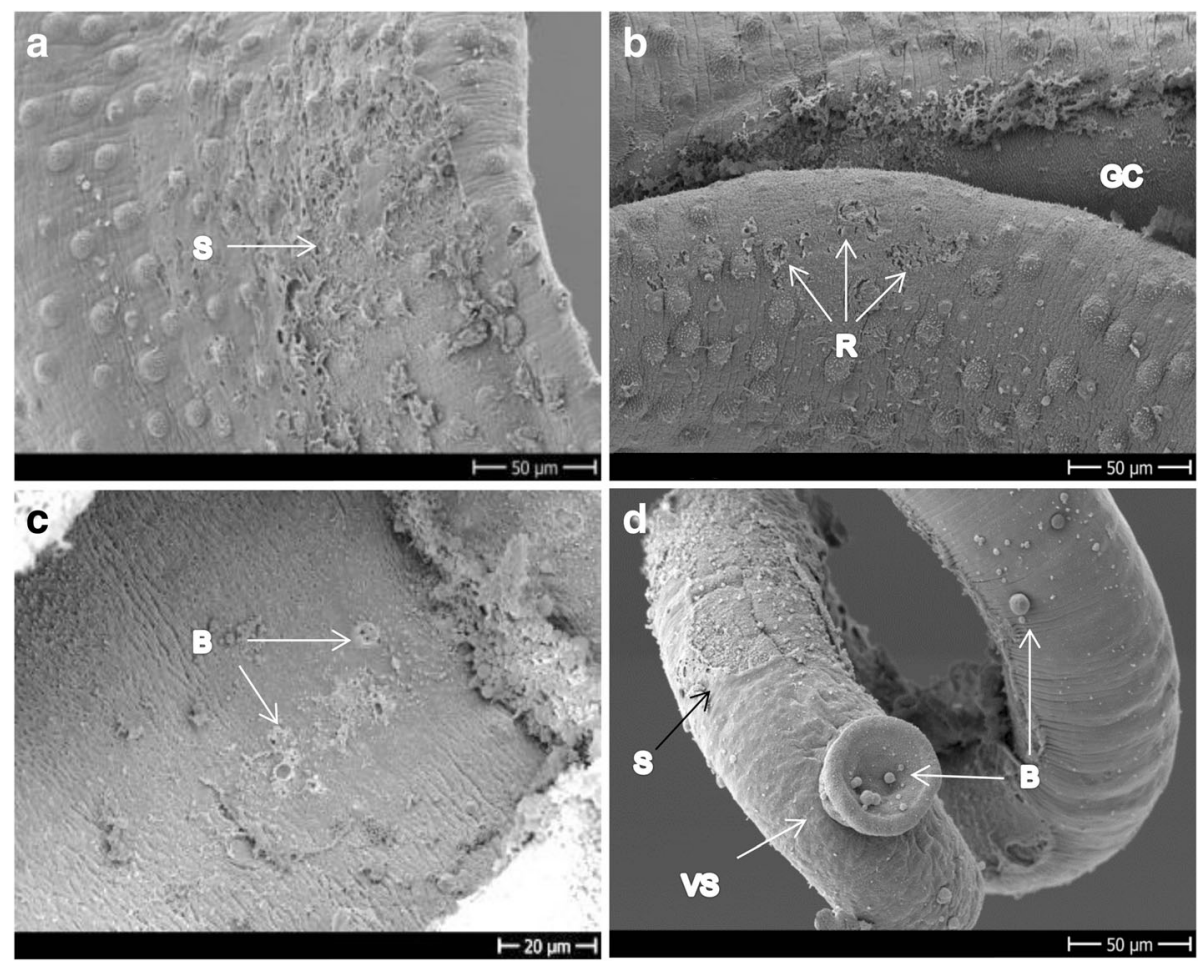

Fig. 3 Adult S. mansoni exposed to $100 \mu \mathrm{M}$ Fc-OXA incubated for 4 h. a Tissue sloughing from the lateral side of the mid-part of the body of a male and exposure of sub-tegumental tissue. $\mathbf{b}$ Mid-part of the body of a male showing the lateral side with ruptures, the gynaecophoric canal and ruptured tissue on the other side of the canal. c Blebs and ruptures in the inner side of the gynaecophoric canal, mid-part of the body. $\mathbf{d}$ Upper part of the body of a female showing tissue sloughing off and blebs on the tegument and ventral sucker. Abbreviations: B, blebs; GC, gynaecophoric canal; R, rupturing; S, sloughing off; VS, ventral sucker. Scale-bars: a, b, d, $50 \mu \mathrm{m} ; \mathbf{c}, 20 \mu \mathrm{m}$ 
by spines that are more or less uniformly distributed. In Fig. $2 c$ the oral and ventral suckers and the gynaecophoric canal of control worms are shown. Ridges are also present on females, but no tubercles or spines; instead, the teguments of the female look more porous and smooth (Fig. 2d).

After $24 \mathrm{~h}$ and $48 \mathrm{~h}$ of exposure to a $100 \mu \mathrm{M}$ concentration of oxamniquine, the worms were alive and phenotypically in a good shape (score above 2) and we did not evidence any damage to the tegument by means of SEM (not shown). After exposure for $120 \mathrm{~h}$ we observed loss of attachment to the well, slight blebbing on the tegument and reduction of movement of the treated worms when compared to the control group. Since the controls also showed mild blebbing and sloughing tissue after this long incubation, we were not able to correlate a certain pattern of damage with the exposure of the worms to OXA. Our data confirm previous findings of OXA being only slightly active in vitro [11] and the difficulties to maintain the worms for long incubation periods where they start revealing tegument damage [15].

Fc-OXA produced after four hours of exposure at a $100 \mu \mathrm{M}$ concentration extensive blebs, sloughing and rupture of the tegument along the whole dorsal body surface on all worms examined (Fig. 3a-c). Along the gynaecophoric canal blebbing and sloughing tissue was evident (Fig. 3c). On the males, no damage to the suckers was observed and the spines did not look significantly damaged (not shown), but were partially covered by the tissue that was detaching, as can be seen in Fig. 3a. On the females, the damage was principally focused on the upper part of the body, where Fc-OXA produced sloughing off and blebbing on the tegument and the ventral sucker (Fig. 3d).

Four hours after exposure to Rc-OXA, the phenotypic score of the worms averaged $0.81 \pm 0.15(n=8$, all worms alive) yet only mild tegumental damage was observed by means of SEM, which consisted of loss of spines and mild blebs in the male, but no damage was evidenced in the females (not shown). After $24 \mathrm{~h}$ of incubation, the male worms had died and the females showed significant morphological changes, very low motility and the maximum score observed was 0.25 . Tegumental damage of the males consisted of increased loss of spines (Fig. 4a) accompanied by tegument sloughing, blebs and vesicle formation all over the body surface (Fig. $4 a-c)$. Although the viability score of the females was below 0.5 , no pronounced tegumental damage could be evidenced using
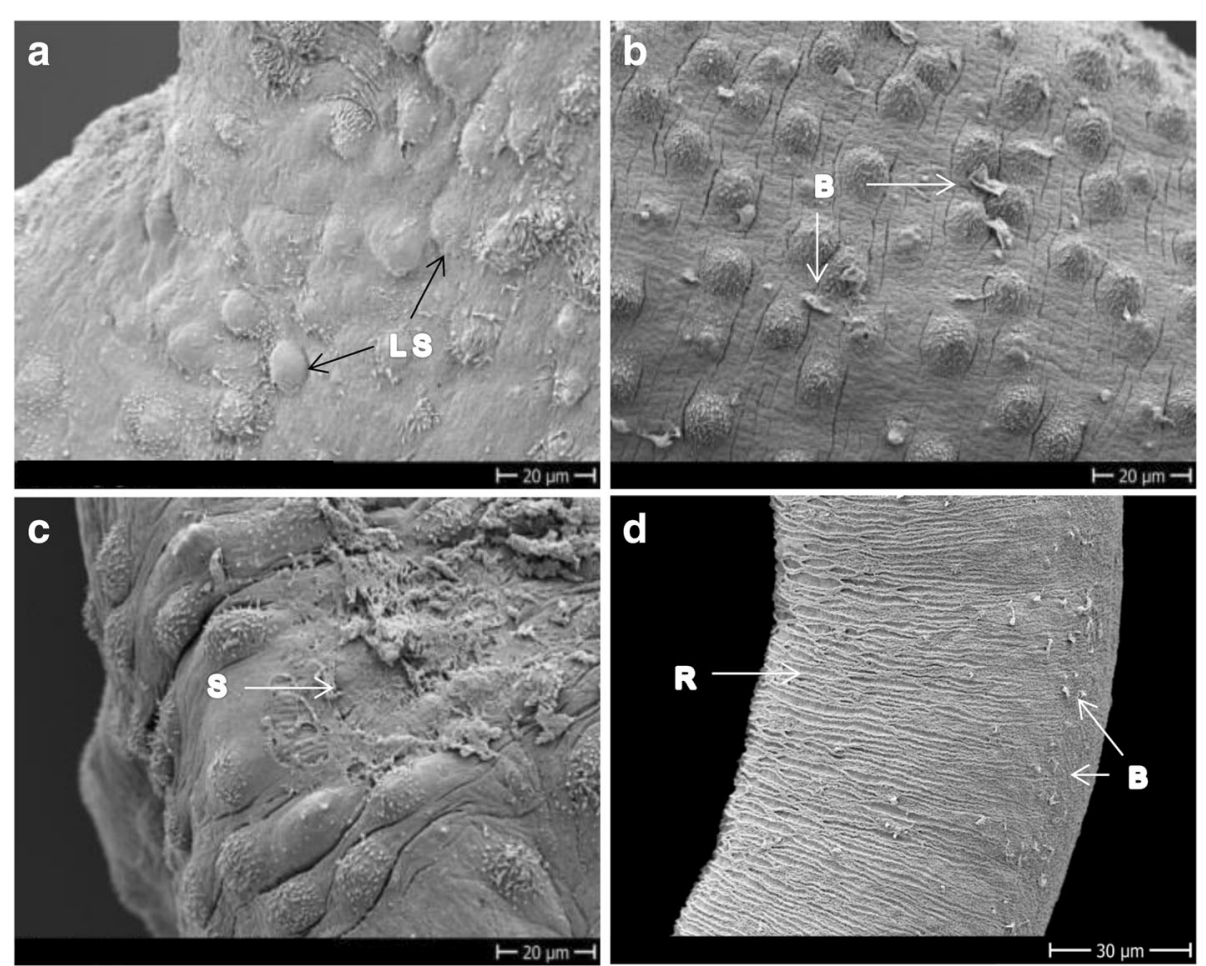

Fig. 4 Adult S. mansoni exposed to $100 \mu \mathrm{M}$ Rc-OXA for 24 h. a-c Dorsal mid-part of males showing blebs, sloughing tissue and loss of spines. d Mid-part of the body of a female showing undamaged ridges and very mild damage characterized by blebs along the body. Abbreviations: B, blebs; LS, loss of spines; R, ridges; S, sloughing off. Scale-bars: a-c, $20 \mu \mathrm{m}$; d, $30 \mu \mathrm{m}$ 
SEM (Fig. 4d). The oral and ventral suckers did not show significant damage and most couples stayed together during drug exposure (not shown) despite death of the male worms. We have no explanation for this observation, but it is possible that the females showed very low vitality and eventually were not able to dissociate from the dead male.

Bn-OXA produced minor damage to the tegument $24 \mathrm{~h}$ after incubation, which consisted of small dimples (Fig. 5a). Only after $72 \mathrm{~h}$ of drug exposure the tegumental damage became evident and consisted, similar to Fc-OXA and Rc-OXA, of blebs (Fig. 5b), sloughing and tegumental rupture distributed all over the dorsal surface (not shown). At this time point, eight worms were dead ( 5 females, 3 males) while five were still alive but highly affected (scoring below 1). Of the three candidates tested, Bn-OXA was the one which showed the most visible damage to the females, which consisted of tegumental rupture (Fig. 5c) and loss of uniformity on the ridges (Fig. 5d), and surprisingly was the only compound with slightly more activity on females than on males within $72 \mathrm{~h}$ of drug exposure. Additionally, Bn-OXA was the only compound that produced loss of spines from the ventral sucker and erosion in the oral sucker of $S$. mansoni (Fig. 5e, f).

Table 1 summarizes $\mathrm{IC}_{50}$ values [11], onset of action and key tegumental changes for all compounds examined on $S$. mansoni. Bn-OXA had the slowest onset
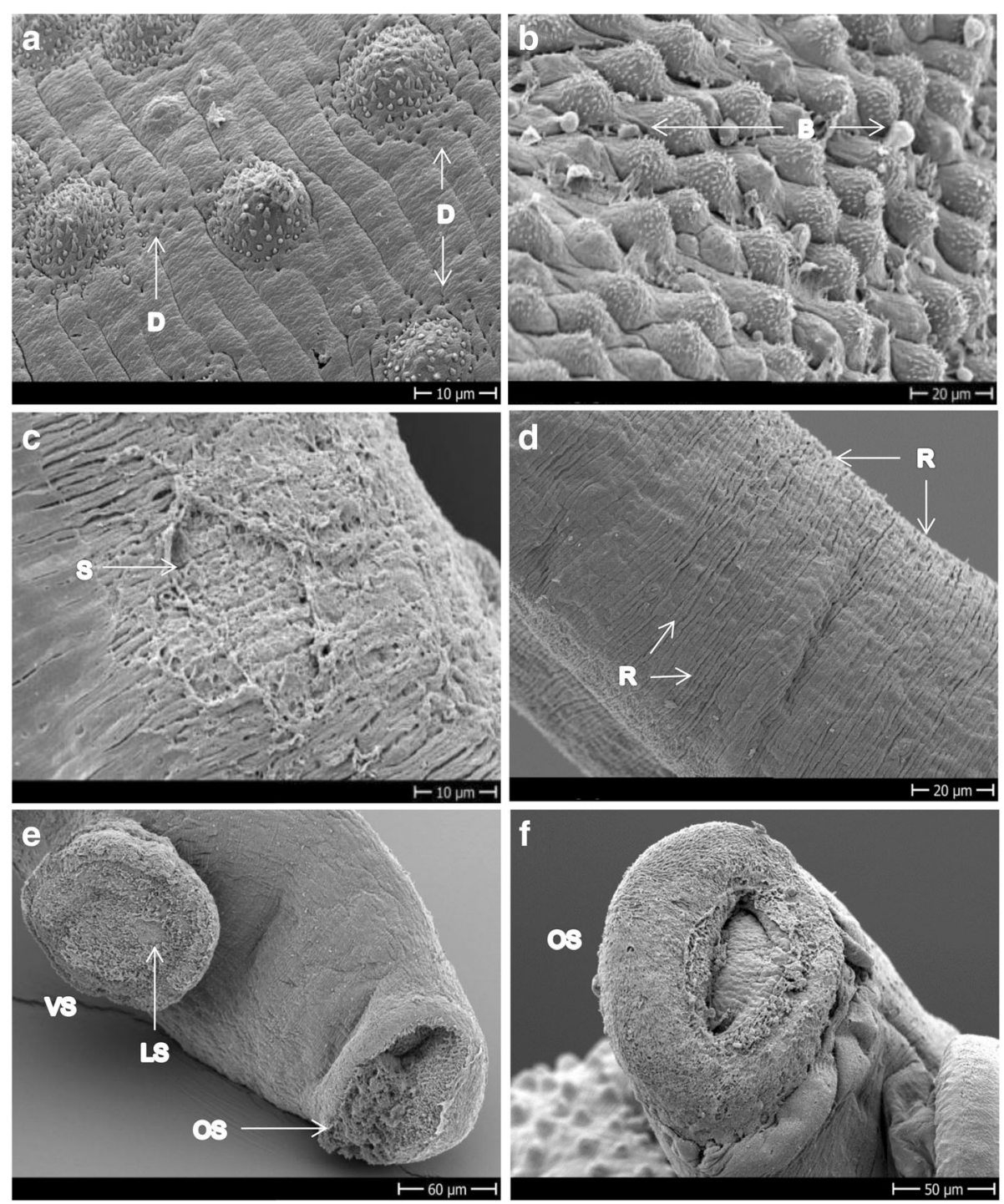

Fig. 5 Adult S. mansoni exposed to $100 \mu \mathrm{M}$ Bn-OXA. a Dorsal mid-part of a male exposed for $24 \mathrm{~h}$ showing very mild damage. b Dorsal mid-part of a male's body incubated for $72 \mathrm{~h}$. c, $\mathbf{d}$ Mid-part of female exposed for $72 \mathrm{~h}$ showing tegument ruptures and loss of uniformity of the ridges. $\mathbf{e}$, f Head of males exposed for $72 \mathrm{~h}$ showing loss of spines from the ventral sucker and rupture and occlusion of the oral sucker. Abbreviations: B, blebs; D, dimples; LS, loss of spines; OSNS, oral/ventral sucker; R, ridges; S, sloughing off; Scale-bars: a, c, $10 \mu \mathrm{m} ; \mathbf{b}, \mathbf{d}, 20 \mu \mathrm{m} ; \mathbf{e}, 60 \mu \mathrm{m} ; \mathbf{f}, 50 \mu \mathrm{m}$ 
Table 1 Comparative activity and effect of the OXA derivatives against S. mansoni

\begin{tabular}{|c|c|c|c|c|c|c|}
\hline \multirow[t]{2}{*}{ Compound } & \multirow{2}{*}{$\begin{array}{l}\text { S. mansoni adult } 72 \\
\mathrm{~h} \mid \mathrm{C}_{50}(\mu \mathrm{M})\end{array}$} & \multirow{2}{*}{$\begin{array}{l}\text { Onset } \\
\text { of action } 100 \mu \mathrm{M}(\mathrm{h})\end{array}$} & \multirow{2}{*}{$\begin{array}{l}\text { Most } \\
\text { affected sex }\end{array}$} & \multicolumn{3}{|c|}{ Tegumental damage } \\
\hline & & & & Blebbing & Sloughing off & Specific damage pattern/organ \\
\hline Fc-OXA & $11.4^{\mathrm{a}}$ & 4 & Males & + & ++ & Gynaecophoric canal \\
\hline Rc-OXA & $8.7^{\mathrm{a}}$ & 24 & Males & ++ & + & Loss of spines \\
\hline Bn-OXA & $11.1^{\mathrm{a}}$ & 72 & Females & + & +++ & Suckers \\
\hline OXA & $>100$ & 120 & Both & $\beta$ & $\beta$ & $\beta$ \\
\hline
\end{tabular}

Abbreviation: $\beta$, no difference was observed to control group

${ }^{a}$ Hess et al. [11]

of action, which slightly contradicts the results presented by Hess et al. [11] who described $80 \%$ reduction in viability already after $24 \mathrm{~h}$ and $100 \%$ effect (all worms dead) in $72 \mathrm{~h}$. The qualitative changes observed differ between the compounds studied and between males and females, a finding which is not uncommon for antischistosomal drugs. Artemether for example, causes extensive peeling in females but not in males [16]. Overall, the tegumental changes observed resemble findings from previous studies with praziquantel and other lead candidates, which also mention loss of spines, blebs and sloughing tissue with exposure of sub-tegumental tissue $[17,18]$.

\section{Studies on S. haematobium}

Figure 6 depicts images of control S. haematobium. Ridges and tubercles with spines on the dorsal side of the tegument and spines uniformly distributed in the gynaecophoric canal are visible (Fig. 6a, b). The apexes of the tubercles of male $S$. haematobium are free of spines (Fig. 6c). The tegument of the females also presents ridges, looks smoother than the males
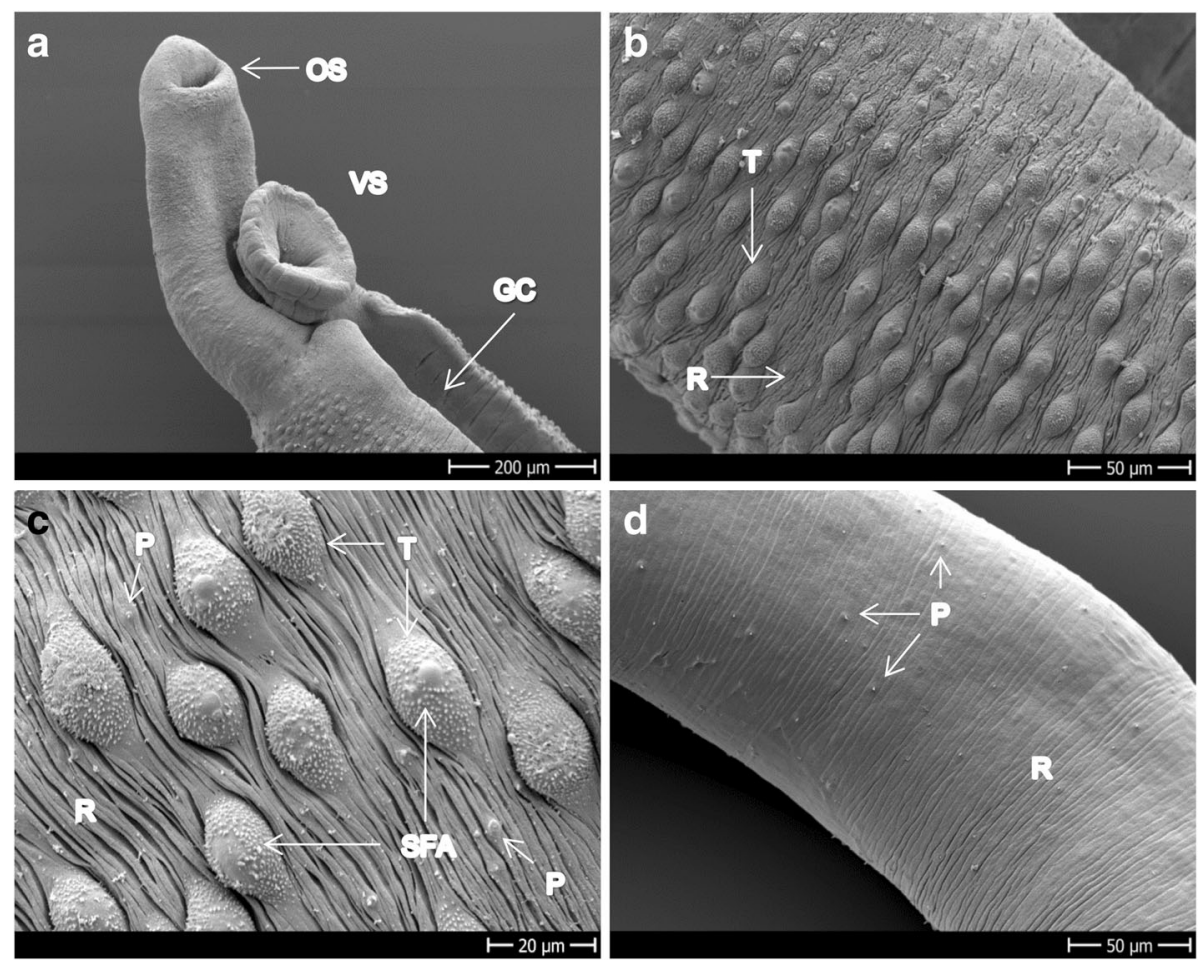

Fig. 6 Control group of adult S. haematobium. a Head of a male showing oral and ventral suckers and the gynaecophoric canal. b Dorsal and lateral side of a male with tubercles and ridges. c Dorsal side of the mid-part of male showing ridges, sensory papillae and apexspine-free tubercles. d Mid-part of the body of a female revealing the smooth tegument with ridges and sensory papillae. Abbreviations: GC, gynaecophoric canal; OS/NS, oral/ventral sucker; P, papillae; R, ridges; SFA, spine free apex; T, tubercles. Scale-bars: $\mathbf{a}, 200 \mu$ m; $\mathbf{b}$, $50 \mu \mathrm{m} ; \mathbf{c}, 20 \mu \mathrm{m} ; \mathbf{d}, 50 \mu \mathrm{m}$ 

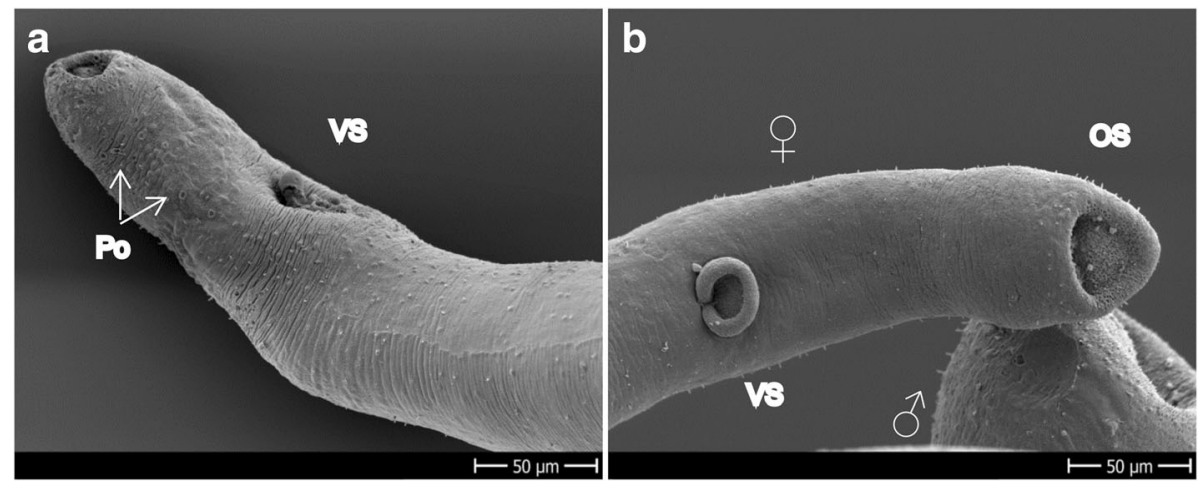

Fig. 7 Schistosoma haematobium exposed to $100 \mu \mathrm{M}$ OXA for $120 \mathrm{~h}$. a Head of a female showing the invaginated ventral sucker. b Head of a female showing the invaginated ventral sucker and mild damage to the oral sucker consisting of blebs and the oral sucker of a male, also showing small ruptures and blebs. Abbreviations: OS, oral sucker; Po, pores; VS, ventral sucker. Scale-bars: $50 \mu \mathrm{m}$

and the sensory papillae are uniformly distributed all over the body (Fig. 6d).

As observed for S. mansoni, S. haematobium incubated for $120 \mathrm{~h}$ in $1 \%$ DMSO also showed slight tegumental damage, characterized by blebs and sloughing tissue (not shown). Therefore few conclusions can be drawn with regard to the damage of $100 \mu \mathrm{M}$ OXA incubated for $120 \mathrm{~h}$. However one sign of damage could be related to OXA, due to the fact it was not evidenced in any of the controls: worms incubated with OXA for 120 $h$ showed invagination of the ventral sucker in females and erosion of the oral sucker in both sexes (Fig. 7a, b).
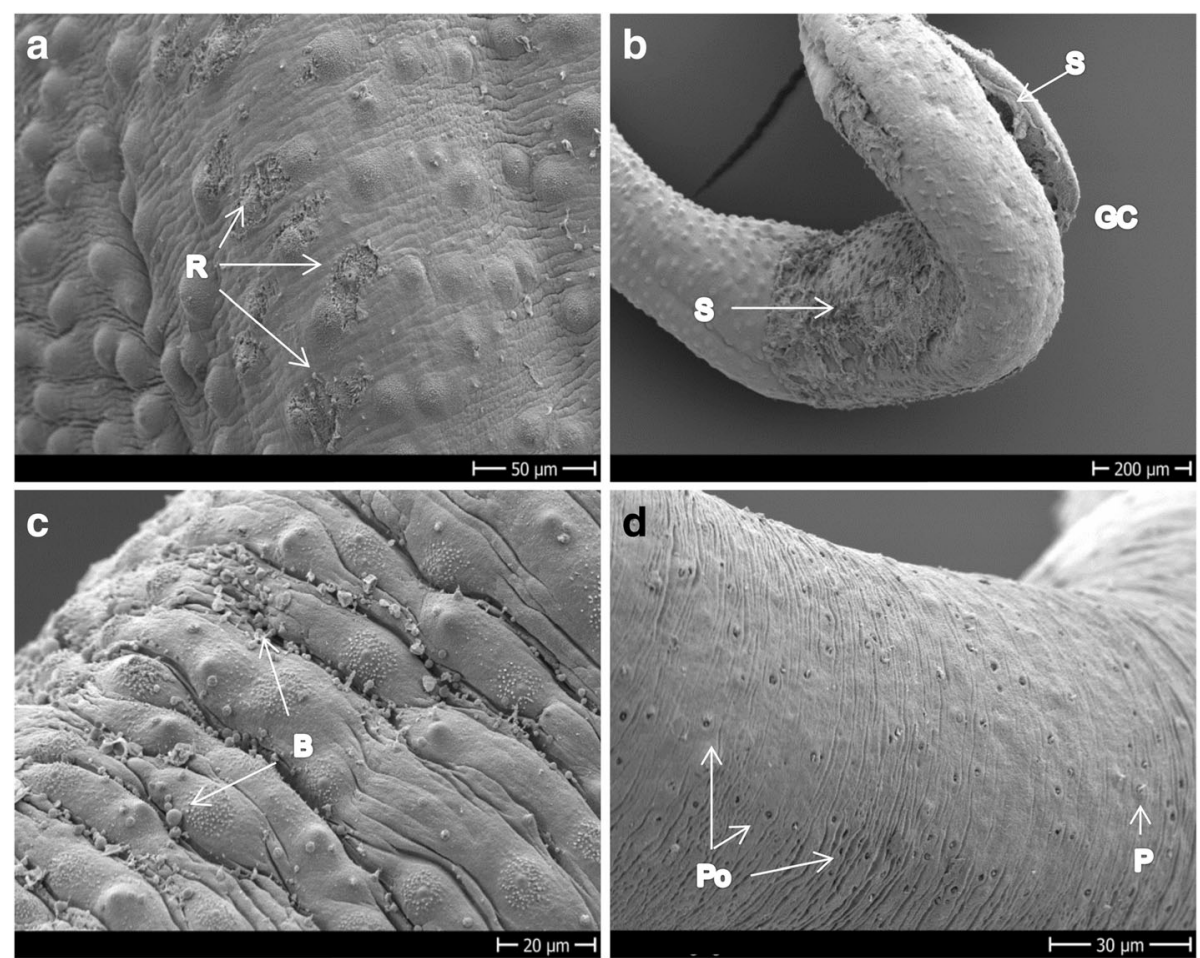

Fig. 8 Adult S. haematobium exposed to $100 \mu \mathrm{M}$ Fc-OXA for $48 \mathrm{~h}$. a Dorsal mid-part of the body of a male showing early rupturing around the tubercles. $\mathbf{b}$ Tegument sloughing at the dorsal mid-part of the body and the gynaecophoric canal. c Blebs on the dorsal mid-part of the body of a male. $\mathbf{d}$ Tegument of a female showing normal ridges and papillae, but also pores; pores seem to be present in higher quantity than in the control group. Abbreviations: B, blebs; GC, gynaecophoric canal; P, papillae; Po, pores; R, rupturing; S, sloughing off. Scale-bars: a, 50 m; b, 200 $\mu \mathrm{m} ; \mathbf{c}, 20 \mu \mathrm{m} ; \mathbf{d}, 30 \mu \mathrm{m}$ 

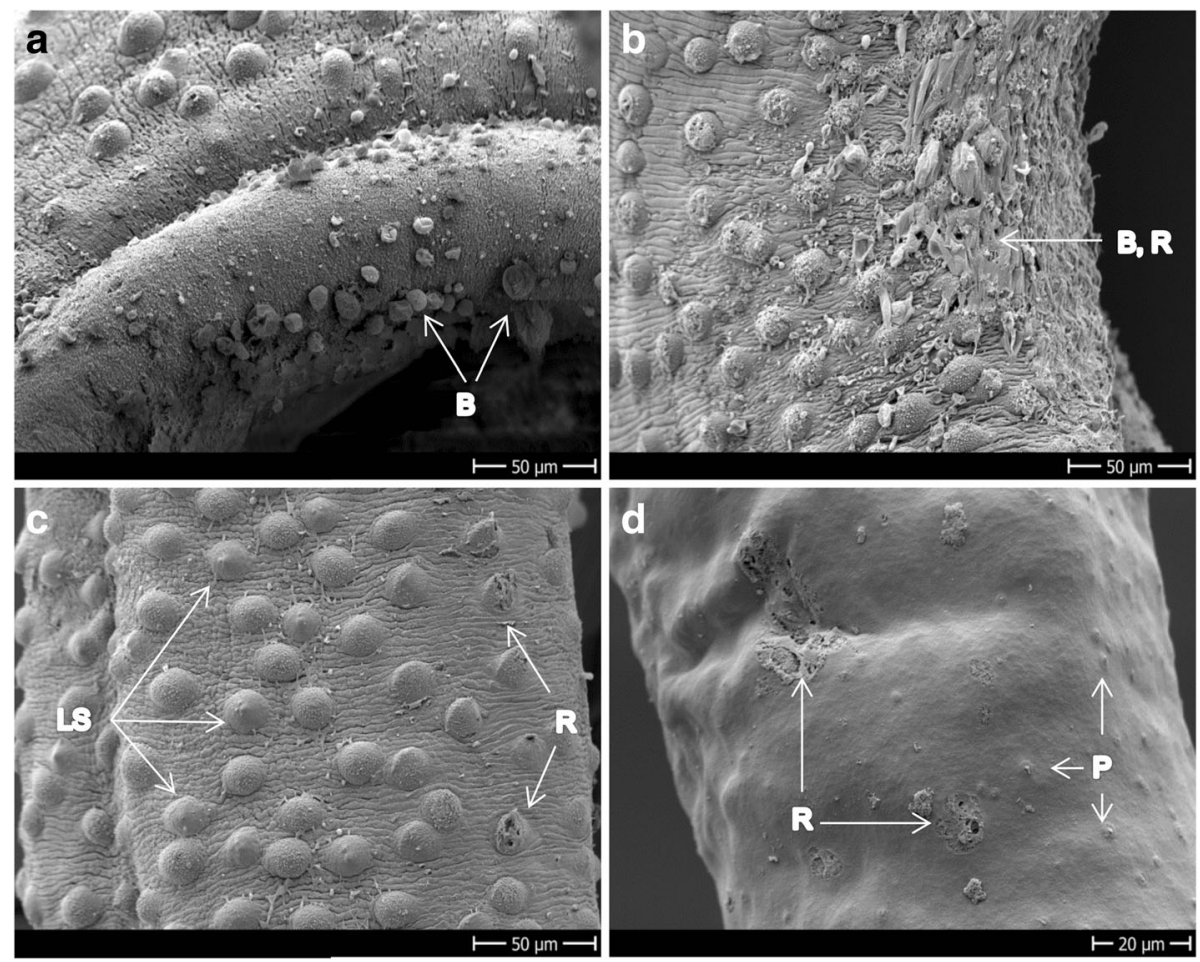

Fig. 9 Adult S. haematobium exposed to $100 \mu \mathrm{M}$ Rc-OXA for $24 \mathrm{~h}$. a-c Dorsal mid part of the body of a male showing blebs, tissue rupture and loss of spines. $\mathbf{d}$ Mid-part of the body of a female showing the tegument rupture. Abbreviations: B, blebs; LS, loss of spines; P, papillae; R, ruptures. Scale-bars: a-c, $50 \mu \mathrm{m} ; \mathbf{d}, 20 \mu \mathrm{m}$

Additionally, we observed a higher number of pores in both sexes of the treated worms with respect to the controls (Fig. 7a).

After $48 \mathrm{~h}$ of exposure to $100 \mu \mathrm{M}$ Fc-OXA we observed damage to the tegument and the gynaecophoric canal along the entire body, which, as in S. mansoni, consisted of blebbing and sloughing off (Fig. 8a-c). The sloughing tissue started its rupture from the areas surrounding the tubercles (Fig. 8a). Compared to the damage of this compound to the gynaecophoric canal in S. mansoni, the damage to this part of the body in $S$. haematobium was more pronounced (Fig. 8b). In females, appearance of pores over all the tegument (Fig. 8d), sporadic blebs and sloughing tissue (not shown) was visible. Damage to the oral or ventral suckers was not seen for Fc-OXA and the overall damage observed was more evident in males than in females.

The treatment of $S$. haematobium with Rc-OXA produced, as in $S$. mansoni, rupture of the tegument, with blebs and sloughing of tissue, and loss of spines within $24 \mathrm{~h}$ of incubation (Fig. 9a-c). In the females (Fig. 9d) we observed damage limited to small ruptures not related to any specific section or structure of the body despite that the viability of both male and female worms had decreased to a score below 0.5 , revealing high activity of the drug. We could not evidence damage to the suckers or gynaecophoric canal following exposure to this compound either in males or in females.

Following incubation of $S$. haematobium males with Bn-OXA, creases of the inner and outside of the body were visible after $48 \mathrm{~h}$ of exposure and there was a tendency of the worms to die in a circular body disposition (Fig. 10a). As in S. mansoni and Fc-OXA and Rc-OXA on S. haematobium, bleb/vesicles formation was a common phenomenon that appeared in large quantities on the entire surface of the tegument (Fig. 10b, c). With regard to tegumental sloughing, the effect of Bn-OXA against S. haematobium was much milder (Fig. 10b, c) when compared to the other compounds (Figs. 8b, 9b) and exposure of S. mansoni to Bn-OXA (Fig. 5c, f). We did not evidence damage to the suckers of the males following exposure to Bn-OXA. However, in females, the erosion and deformity to both oral and ventral suckers was significant (Fig. 10d) and was also accompanied by sloughing tissue.

Different from the activity of Bn-OXA against $S$. mansoni, in $S$. haematobium this compound was more active against males than against females, but as for S. mansoni, Bn-OXA seemed to reveal the highest activity of the three derivatives against females.

Table 2 summarizes in vitro effects of the three compounds on S. haematobium. After exposure to a $100 \mu \mathrm{M}$ 

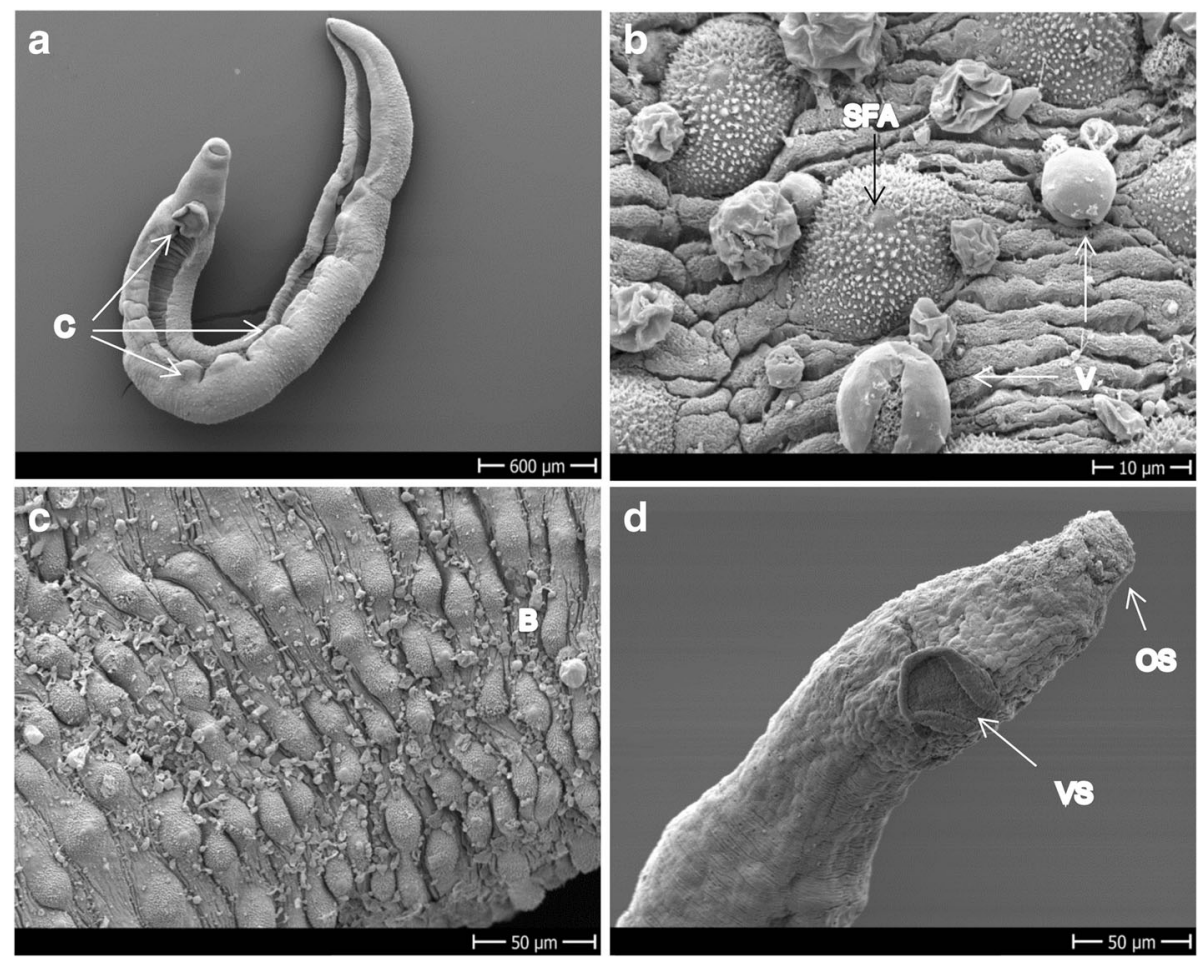

Fig. 10 Adult S. haematobium exposed to $100 \mu \mathrm{M}$ Bn-OXA for $48 \mathrm{~h}$. a Male showing creases of the tegument and the circular disposition of the body before dying. b, c Dorsal mid-part of male's tegument showing the extensive distribution of blebs, vesicles and mild sloughing off. $\mathbf{d}$ Head of a female showing extensive erosion of the oral sucker and extensive deformity of the ventral sucker. Abbreviations: B, blebs; C, creases; OS/VS, oral/ventral sucker; SFA, spine free apex; V, vesicles. Scale-bars: $\mathbf{a}, 600 \mu \mathrm{m} ; \mathbf{b}, 10 \mu \mathrm{m} ; \mathbf{c}$, d, $50 \mu \mathrm{m}$

concentration, Fc-OXA needed $48 \mathrm{~h}$ to trigger a reduction in viability of $75-85 \%$ on $S$. haematobium, while Rc-OXA was lethal for all males and reduced the viability of the females to a score lower than 0.5 within $24 \mathrm{~h}$. Rc-OXA also had the lowest $\mathrm{IC}_{50}$ value of the three compounds. Bn-OXA reduced the viability of males and females by $70 \%$ within $48 \mathrm{~h}$. All derivatives were more active on males than on females, while in the case of oxamniquine no difference of sex susceptibility could be determined. Also, for S. haematobium we observed loss of spines and sloughing tissue, which are signs of drug activity that have been described before, for example for artemisinins against $S$. haematobium [19]. Other studies reported the damage of active compounds to $S$. haematobium to be characterized by edematous intertubercular spaces and collapse of tubercles, signs that were not observed in our compounds [20].

\section{Comparison of oxamniquine derivatives}

While the fastest and most active compound against $S$. mansoni was Fc-OXA, Rc-OXA was the most promising compound for $S$. haematobium with regard to in vitro activity and tegumental damage. Surprisingly, Fc-OXA had the highest $\mathrm{IC}_{50}$ value against $S$. haematobium. Bn-OXA was the compound with the slowest visible effect against both species, but was active against both species as well, in a timeframe of 48-72 h, depending on the species. Overall, a higher activity of the derivatives was observed against $S$. mansoni than against $S$. haematobium.

Table 2 Comparative activity and effect of the derivatives against S. haematobium

\begin{tabular}{lllllll}
\hline Compound & $\begin{array}{l}\text { S. } \\
\text { haematobium } \\
\text { adult } 72 \mathrm{~h} \mathrm{IC}_{50}(\mu \mathrm{M})\end{array}$ & $\begin{array}{l}\text { Onset } \\
\text { of action } 100 \mu \mathrm{M}(\mathrm{h})\end{array}$ & $\begin{array}{l}\text { Most } \\
\text { affected sex }\end{array}$ & & \multicolumn{2}{l}{ Tegumental damage } \\
\cline { 6 - 7 } & 68.1 & 48 & Males & + & ++ & Gynaecophoric canal \\
\hline Fc-OXA & 24.5 & 24 & Males & ++ & ++ & Loss of spines \\
Rc-OXA & 38.6 & 48 & Males & + & +++ & Body creases \\
Bn-OXA & $>100$ & 120 & Both & + & $\beta$ & VS invagination \\
OXA & 100 & &
\end{tabular}

Abbreviations: VS, ventral sucker; $\beta$, no difference was observed to control group 
For both species, and all three derivatives investigated, we could observe common patterns of damage to the tegument, which consisted of extensive blebs and considerable tegument rupture and sloughing off along the whole body, with exposure of sub-tegumental tissue. The sub-tegument might expose antigens and therefore trigger an immune response attack, commonly observed for antischistosomal drugs [17-19].

Differences in the damage distribution cannot be explained, but might be due to a differential distribution of the activating enzyme in the body of the parasites or additional mechanisms of action for the individual derivatives supporting the antiparasitic effect.

\section{Conclusions}

Our study confirmed that Fc-OXA, Rc-OXA and Bn-OXA are promising broad spectrum antischistosomal drug candidates. All derivatives showed high in vitro activity against $S$. mansoni and S. haematobium, while validating the previous finding that the parent drug oxamniquine is less active in vitro under the conditions described. Future studies should aim to further characterize these compounds, taking into account the in vivo activity on juvenile stages of development and activity against $S$. haematobium in vivo.

\section{Abbreviations}

OXA: Oxamniquine; Fc-OXA: Ferrocenyl oxamniquine; Rc-OXA: Ruthenocenyl oxamniquine; Bn-OXA: Benzyl oxamniquine; SEM: Scanning electron microscopy; SmSULT: Schistosoma mansoni sulfotransferase; DMSO: Dimethyl sulfoxide

\section{Acknowledgments}

We kindly acknowledge the help and expertise from Eva Bieler from the Swiss Nano science Institute.

\section{Funding}

We gratefully acknowledge financial support from the Swiss National Science Foundation (Professorships No. PP00P2_133568 and PP00P2_157545 to GG), the University of Zurich (GG) and the Swiss excellence scholarships for foreign students (ESKAS to VB). This work has received support under the program "Investissements d'Avenir" launched by the French Government and implemented by the ANR with the reference ANR-10-IDEX-0001-02 PSL (GG). JK and GG are grateful to the European Research Council (ERC-2013CoG 614739-A_HERO to JK and ERC-2015-CoG 681679-PhotoMedMet to GG) for financial support.

\section{Availability of data and materials}

The data supporting the conclusions of this article are included within the article. Raw data are available upon request from the corresponding author.

\section{Authors' contributions}

JK and VB designed the studies and collected and analysed the data. VB took the images with the assistance of a professional technician in the imaging facilities and drafted the first version of the manuscript that JK supervised. GG and JH designed and synthetized the derivatives of oxamniquine and revised the manuscript. All authors read and approved the final manuscript.

\section{Ethics approval}

All animal experiments were authorized by the veterinary office from Canton Basel Stadt (Authorization No. 2070) based on the Swiss national and cantonal regulations.
Consent for publication

Not applicable.

\section{Competing interests}

The authors declare that they have no competing interests.

\section{Publisher's Note}

Springer Nature remains neutral with regard to jurisdictional claims in published maps and institutional affiliations.

\section{Author details}

'Department of Medical Parasitology and Infection Biology, Swiss Tropical and Public Health institute, Socinstrasse 57, 4051 Basel, CH, Switzerland. ${ }^{2}$ University of Basel, P.O. Box, 4003 Basel, CH, Switzerland. ${ }^{3}$ Department of Chemistry, University of Zurich, Winterthurerstrasse 190, 8057 Zurich, CH, Switzerland. ${ }^{4}$ Chimie ParisTech, PSL University, Laboratory of Inorganic Chemical Biology, F-75005 Paris, France.

Received: 9 July 2018 Accepted: 2 October 2018

Published online: 06 November 2018

\section{References}

1. Colley DG, Bustinduy AL, Secor WE, King CH. Human schistosomiasis. Lancet 2014;383:2253-64.

2. Bergquist $\mathrm{R}$, Utzinger J, Keiser J. Controlling schistosomiasis with praziquantel: how much longer without a viable alternative? Infect Dis Poverty. 2017;6:74.

3. Stothard JR, Sousa-Figueiredo JC, Betson M, Bustinduy A, Reinhard-Rupp J. Schistosomiasis in African infants and preschool children: Let them now be treated! Trends Parasitol. 2013:29:197-205.

4. Cioli D, Pica-Mattoccia L, Basso A, Guidi A. Schistosomiasis control: praziquantel forever? Mol Biochem Parasitol. 2014;195:23-9.

5. Lago EM, Xavier RP, Teixeira TR, Silva LM, da Silva Filho AA, de Moraes J. Antischistosomal agents: state of art and perspectives. Future Med Chem. 2017;10:89-120.

6. Pica-Mattoccia L, Novi A, Cioli D. Enzymatic basis for the lack of oxamniquine activity in Schistosoma haematobium infections. Parasitol Res. 1997;83:687-9.

7. Sabah AA, Fletcher C, Webbe G, Doenhoff MJ. Schistosoma mansoni: chemotherapy of infections of different ages. Exp Parasitol. 1986;61:294-303.

8. Chevalier FD, Le Clec'h W, Eng N, Rugel AR, Assis RR de, Oliveira G, et al. Independent origins of loss-of-function mutations conferring oxamniquine resistance in a Brazilian schistosome population. Int J Parasitol. 2016;46:417-424.

9. Valentim CLL, Cioli D, Chevalier FD, Cao X, Taylor AB, Holloway SP, et al. Genetic and molecular basis of drug resistance and species-specific drug action in schistosome parasites. Science. 2013;342:1385-9.

10. Manneck T, Braissant O, Haggenmüller Y, Keiser J. Isothermal microcalorimetry to study drugs against Schistosoma mansoni. J Clin Microbiol. 2011;49:1217-25.

11. Hess J, Panic G, Patra M, Mastrobuoni L, Spingler B, Roy S, et al. Ferrocenyl, ruthenocenyl, and benzyl oxamniquine derivatives with cross-species activity against Schistosoma mansoni and Schistosoma haematobium. ACS Infect Dis. 2017;3:645-52

12. Hess J, Keiser J, Gasser G. Toward organometallic antischistosomal drug candidates. Future Med Chem. 2015:7:821-30.

13. Jones MK, Gobert GN, Zhang L, Sunderland P, McManus DP. The cytoskeleton and motor proteins of human schistosomes and their roles in surface maintenance and host-parasite interactions. BioEssays. 2004;26:752-65.

14. Keiser J. In vitro and in vivo trematode models for chemotherapeutic studies. Parasitology. 2010;137:589-603.

15. Gobert GN, Schulte L, Jones MK. Tegument and external features of Schistosoma (with particular reference to ultrastructure). In: Jamieson BGN, editor. Schistosoma: Biology, Pathology, and Control. Boca Raton: CRC Press; 2017. p. 213-38.

16. Abdul-Ghani R, Loutfy N, Sheta M, Hassan A. Artemether shows promising female schistosomicidal and ovicidal effects on the Egyptian strain of Schistosoma mansoni after maturity of infection. Parasitol Res. 2011;108:1199-205.

17. Silva A, Oliveira S, Oliveira J, Santiago E, Júnior A, Jacobi Í, et al. Tegumental changes in adult Schistosoma mansoni induced by a new imidazolidinic derivative. Br J Pharm Res. 2014;4:1988-2005.

18. de Oliveira SA, de Oliveira Barbosa M, Filho CALM, Oliveira AR, de Sousa FA, de Farias Santiago E, et al. Phthalimido-thiazole as privileged scaffold: 
activity against immature and adult worms of Schistosoma mansoni. Parasitol Res. 2018;117:2105-15.

19. El-Beshbishi SN, El Bardicy S, Tadros M, Ayoub M, Taman A. Efficacy of artemisinin-naphthoquine phosphate against Schistosoma haematobium adult flukes: dose-effect relationship and tegumental alterations. J Helminthol. 2018. https://doi.org/10.1017/S0022149X18000421.

20. Eraky MA, Aly NSM, Selem RF, El-Kholy AAE-M, Rashed GAE-R. In vitro schistosomicidal activity of phytol and tegumental alterations induced in juvenile and adult stages of Schistosoma haematobium. Korean J Parasitol. 2016:54:477-84.

Ready to submit your research? Choose BMC and benefit from:

- fast, convenient online submission

- thorough peer review by experienced researchers in your field

- rapid publication on acceptance

- support for research data, including large and complex data types

- gold Open Access which fosters wider collaboration and increased citations

- maximum visibility for your research: over $100 \mathrm{M}$ website views per year

At BMC, research is always in progress.

Learn more biomedcentral.com/submissions 